Monitored Emergency Use of Unregistered and Investigational Interventions for Ebola Virus Disease (EVD). Geneva: WHO; 2018 Aug 27[cited 2020 Apr21]. Available from: https://www.who.int/ebola/drc2018/notes-for-the-record-meuri-ebola.pdf
33. Indian Council of Medical Research. National Ethical Guidelines for Biomedical and Health Research Involving Human Participants 2017. New Delhi: ICMR; 2017.

\title{
Twin public health emergencies: Covid-19 and domestic violence
}

\section{RAKHI GHOSHAL}

\begin{abstract}
While a virus is hardly "choosy" in finding a host, the consequences of government responses to a pandemic, such as to Covid-19, have deep implications for those already-marginalised, such as women and girls. In the absence of a systematic database examining the details of the impact, this comment synthesises existing opinions, reviews and the limited available data to show how, not only the outbreak, but particularly our response to it, are increasing the incidence of domestic violence (DV) across the globe, including in India. Despite tackling a much higher Covid caseload and mortality rate than India has, countries such as France and Spain have prioritised responding to $D V$ in their respective societies, working out contingent mitigation mechanisms. Admittedly, low resource settings (LRS) such as India, have a bevy of additional infrastructure and budgetary challenges; but would that imply we do not respond to DV? This comment argues that in reality we have two public health emergencies to confront, the Covid-19 and domestic violence. It builds on the author's observations in the course of working on DV in an LRS context in India, and concludes with a set of recommendations on better responding to DV during Covid/lockdown times.
\end{abstract}

Keywords: Domestic violence, gender-based violence, Covid-19, lockdown, pandemic, low resource settings

\section{An invisible battle is launched}

Covid -19 is a major public health crisis which has enveloped millions of us. While both the rich and the poor have been affected by the virus, the consequences of this outbreak (or of any disease outbreak for that matter) are hardly as equalising. As a response to containing the infection spread, several governments have instituted home quarantine and lockdowns. Naturally, mobility is restricted and put under surveillance, and people are stuck at home. The consequences of these measures most affect the already-vulnerable the poor, women

Author: Rakhi Ghoshal (rakhi.ghoshal@gmail.com), Project Manager, CARE India, Patna, Bihar 800013 INDIA.

To cite: Ghoshal R. Twin public health emergencies: Covid-19 and domestic violence. Indian J Med Ethics. 2020 Jul-Sep; 5(3) NS: 195-9. DOI: 10.20529/ IJME.2020.056.

Published online on May 7, 2020.

(C) Indian Journal of Medical Ethics 2020 and children, the daily wage earners, the homeless. It is the first time in several decades that a pandemic has affected more than 200 countries; even though earlier outbreaks such as the Ebola and Zika also shored up deeply gendered aftermaths, systematic research on this is still at a nascent stage (1).

Seeking to partially address this gap, this comment synthesises some of the existing reviews, articles and data, especially those published from the development and humanitarian sector, to study how gender is affected in multiple ways in the Covid situation. This comment focuses particularly on how the response to Covid has triggered higher rates of domestic violence across the globe, including India. Along with the world, India too is, unfortunately, in the grip of two public health emergencies - Covid and domestic violence. This comment, in conclusion, discusses a list of plausible solutions that are applicable to low resource settings for addressing or at least mitigating - the acute challenges of aggravated domestic violence.

\section{The gendering of a disease outbreak}

Responses to public health emergencies commonly "divert resources from routine health services" $(2,3)$, and this has happened during Ebola and Zika too. In responding to Covid as well, services such as pre- and post-natal care, contraceptives, and access to sexual and reproductive health services have been seriously affected (2). The Lancet flagged this back grounding of basic medical services as a major concern and urged policy makers not to overlook non-Covid critical illnesses, especially in LRS (4). Recognising this, the Ministry of Health and Family Welfare issued a Guideline on Delivery of Essential Services (https://www.mohfw.gov.in/pdf/ EssentialservicesduringCOVID19updated0411201.pdf) where basic maternity services have been asked to be resumed. However, given the lack of transportation, their uptake will continue to face severe challenges. The effect of this will largely be borne by women and children.

Data from a cholera epidemic in Haiti in 2010 and the Ebola outbreak in West Africa in 2016 showed that such public health emergencies "place a three-fold caregiver burden on women and girls": from exposing them to greater risks of infection coupled with lower rates of treatment, to higher degrees of physical, socioeconomic and emotional distress and harm, the pandemic/epidemic collaterals are highly gendered (5). Under lockdowns such as we are in, women's basic sanitary 
and hygiene needs, including menstrual health needs, are commonly sidetracked, and more so in LRS (6). Lack of focus on sanitary and menstrual needs negatively affects sexual and reproductive health. An interim gender analysis of the Covid data points out that "development or humanitarian contexts could disproportionately affect women and girls in a number of ways, including adverse effects on their education, food security and nutrition, health, livelihoods, and protection. Even after the outbreak [Covid] has been contained, women and girls may continue to suffer from its ill-effects for years to come." (7).

\section{Locked down}

The daily reality of all members of households stuck at home over an extended period of time also translates to women having to attend to routine caregiving of so many more members, managing food so many more times per day, and attending to the increased burden of housekeeping; procuring higher volumes of potable water, especially in areas of water scarcity, is an aggravated challenge. With incidence of sexual abuse and exploitation also increasing during public health emergencies, "women and girls will become more vulnerable when travelling to collect water for household use or to use latrines"(7).

More than $90 \%$ of employed Indians work in the informal sector and stand the risk of losing their jobs - unless already lost. Of all women who work, 94\% work in the informal sector and will bear the brunt of going incomeless: "Women are more likely to be engaged in the informal sector and be hardest hit economically by COVID-19" observed the InterAgency Standing Committee, a forum of the UN and non-UN humanitarian partners (8).

A similar financial threat grips the men of the same households, creating a pressure cooker of uncertainty, frustration and stress. A combination of these three emotions, especially in patriarchal cultures such as we have, commonly leads to a perverted expression of violence upon the dependents at hand - viz the elderly, children and the women of the household. As a result, abuse rates are shooting up. The WHO has prioritised the urgency to recognise that "violence against women remains a major global public health and women's health threat during emergencies" (9). The Covid crisis has already begun to leave in its trail a chain of gendered consequences, including an increased risk of domestic violence (DV).

As we decide to lock down people in our concerted effort to delay the spread of infection, we have prompted another public health crisis. It is a painful Catch-22 situation.

\section{Catch 22: globally rising levels of 'DV'}

Domestic violence (DV) has a wide spectrum of disturbing consequences, from immediate injury to long-term trauma, from physical to psychological, affecting the survivor, the members of her family, and could have intergenerational effects too. The WHO research shows that those who experience violence or abuse "are twice as likely to have an abortion, and the experience nearly doubles their likelihood of falling into depression. In some regions, they are 1.5 times more likely to acquire HIV, and evidence exists that sexually assaulted women are 2.3 times more likely to have alcohol disorders" (10).

Rates of DV have already gone up in many Covid-affected countries such as Brazil, Germany, Italy, China, the United Kingdom, the United States and Australia $(11,12)$. In China's Hubei province, DV rates during lockdown tripled compared to the previous year for the same period and same area (11). Reports of increased volumes of domestic violence have also come in from Lebanon and Malaysia as per UN data (10). In the UK, the National Domestic Abuse Helpline saw an increase of $25 \%$ in calls and online messages after the lockdown began (13). According to Graham-Harrison (11), in Cyprus, when the first Covid positive case was identified, panic spread, people were asked to stay indoors, and soon after calls to the violence helpline numbers shot up by over $30 \%$. Needless to add, calls are being made by women who have access to a cellphone/ telephone, who can leave the house for a short while, or can ensure a private space in the house from which to place the call. Several more women are unable to reach out as they can manage neither of these.

Again, while the reporting of violence has shot up, the availability of support services, and accessibility to those services, have gone down. According to ABC News, Australia, some perpetrators are apparently using Covid as a psychological tool against their "victims": they are telling their wives/victims that they [the latter] are infected with Covid and so, should not leave the house. They are also threatening to get them infected unless they do their bidding (14).

Addressing the acute need of the hour, rights-based groups in Germany have issued a call to the government to prioritise women's safety and to earmark resources to equip more safe houses - including converting hotels and guesthouses into safe houses. They have argued that much more important than following the no-contact rule is the need to save survivors; these groups have prioritised home visits of known cases despite the lockdown. Spain, which had been imposing penalties for those breaking lockdown rules, eventually relaxed its restriction for women, in case they were leaving their houses because of violence.

Organisations in the UK have called for special police powers to help rescue domestic violence survivors. In Italy, a trade union group has demanded that for the duration of the pandemic, the perpetrator, and not the survivor, should be made to stay in a shelter. Police forces in Greece are investing on public campaigns to raise awareness about domestic violence during the pandemic, and on strategies which would assist survivors in seeking help (11). The Scottish government has pledged grants of over GBP 1.5 million for organisations working to help survivors of abuse and rape, to ensure that access to support services is maintained during this Covid outbreak period (13). 


\section{Domestic violence and the case of India}

According to $2013 \mathrm{WHO}$ data, 35\% of the world's women are subjected to violence by their partners, at least once in a lifetime, and of all the women who are murdered globally, 38\% are murdered by their husbands/partners (15). In 2017, of the 87,000 women killed across the globe, more than half were killed by intimate partners or family members (10). Domestic violence (DV) is more extensive than intimate partner violence (IPV), including any member of the survivor's natal or marital family, and not just the partner; so DV rates are either the same as IPV rates, or higher - commonly much higher than IPV rates in India, given the structure of joint families prevalent in many parts of the country.

Indian data corroborates the global statistics; data from the National Family Health Survey, round 4 (NFHS) (2015-16) shows that one in every three women in India reports violence by the husband/partner at least once in her lifetime. In other words, India has high DV rates in non-pandemic times as well (16). Thus, to hear that DV cases are rising in India as we have been locked down for several weeks, is alarming.

In just one week of the pan-India lockdown, the National Commission for Women (NCW) in India received 58 complaints (17), close to double its number of weekly complaints. According to this article, the NCW chairperson stated that, till date, the recorded incidence of DV during Covid has been highest from Punjab. However, as all the 58 complaints were received over email, the Chairperson remains apprehensive that the real numbers, including women with no access to emails, and are unable to use the post due to the lockdown would be significantly higher. Reduced mobility is restricting the survivor's ability to leave the place of abuse, and travel to the natal household or to a safe address during times of exaggerated violence; or to access a healthcare facility for treatment of violence inflicted injuries. And so, while some organisations have reported a drastic rise in complaints, other helplines and organisations - such as Delhi based Jagori and Shakti Shalini, and Pune based AKS Foundation have recorded a drop in the number of calls. AKS Foundation recorded a drop from 15-20 calls per week to seven calls, and Jagori a "more than 50 percent drop" in their call volumes (18). The reduction is explained by a lack of scope, privacy and access to even make calls $(18,19,20)$. A detailed analysis of the data of calls and emails - which women are able to reach out, which women are not - would lead to a nuanced reading of the socio-economic class, as well as educational status, and level of awareness about support services that the survivors have.

\section{First, acknowledge a parallel public health crisis}

Responding to reports flooding in of the sudden spike in domestic and family violence across countries, the WHO Director General made a public appeal on April 5 to help survivors at any cost: he urged the survivors themselves to make plans for their own safety - such as reaching out to a neighbour or relative, leaving the house, and/or going to a safe shelter (21). The same day, the Secretary-General of the United Nations also addressed this issue; he appealed to all governments to prevent a "horrifying global surge in domestic violence" (10). In his video address the Secretary-General added that all governments need to make prevention of violence against women "a key part of their national response plans for Covid-19" (emphasis added; 10). While the WHO and the UN have recognised that women face an aggravated threat of violence in Covid times, especially in their homes, the government in India has so far not even acknowledged this as a parallel human rights crisis.

Though we present a resource-challenged context, we cannot use that aspect to justify a refusal to focus on aggravated domestic violence; we need to negotiate our constraints and push boundaries to confront it. For instance, while Uttar Pradesh has one of the highest rates of domestic violence in the country, the UP police did make an effort to reach out to women - by publicising the slogan, "Suppress corona, not your voice". It highlighted its existing helpline number '112' and reiterated that survivors should reach out on that number (20). Though the helpline number is meant for all types of emergencies, just to highlight it and emphasise the need to reach out in times of need, is an important starting point. The Kerala government has actively focused on domestic violence and hashtags and other awareness campaigns have been given priority.

\section{Thinking through some recommendations}

In this concluding section, I list five specific points based on existing recommendations, but adapted to LRS settings within India, drawing on my personal experience of working on gender-based violence.

- Helplines and other platforms: After ensuring that there is a phone number flagged, the next step is to ensure that the number is functional for as many hours as possible; next is to add more numbers so that more survivors can reach out at the same time. As women would find it challenging to make the distress call in a very limited time slot, it is important to make available more contact numbers. Helplines would be able to offer preliminary counselling, and emotional support, and link up with other available social and legal support services. The instances of support mentioned above by the WHO Director General are closely aligned with the LIVES protocol of the WHO (15). As per this protocol, LIVES implies a comprehensive package of psychological first aid: Listening, Inquiry (about the history of violence, and other relevant information); Validation (of the survivor's experience and narration of violence); Enhancing safety (including a safety plan customised for the specific context of each survivor); and Support (including intersectoral referrals). Most of the components of the WHO LIVES protocol can be delivered over the phone, even as certain changes would have to be made to address the current context such as increased domestic workload, increased caregiving load, etc. Additionally, opening up email IDs (for those who can access the 
technology) as well as other social media links would broaden the support net.

- Awareness drives and active messaging: This is a low-cost modality: spreading awareness that violence is not justified whatever the "reason", and should not be tolerated at any count; and that support is available. It should receive the widest possible publicity. This is absolutely doable in India given the wide coverage mobile phones and televisions have - texts and videos are circulated across social medial platforms such as WhatsApp in large volumes: circulating such awareness campaigns and videos is not a major challenge. Several NGOs could be involved in developing such content. Organisations such as Jagori, and Dilaasa, which have been working on very similar issues over several years, could be involved in charting out the details. Numbers of NGOs who can be approached for help and support during times of domestic violence are circulating on the internet, but not being backed by the government. For the government to actively publicise these contacts would give out a far stronger message.

- Community involvement: Since the ability of helplines as well as facility-based counsellors, and other organisations to help the survivor of abuse would be very limited under the present restrictions, one would need to explore ways to seek community support: it is the community which remains best equipped to support a survivor of violence. Collaborating with the local community based organisations is very likely to emerge as a strong emotional safety net. The community can provide the most accessible support to survivors in the present times, as they are often unable to travel to the hospital or police station to seek help or call up a helpline. Organisations and helplines need to collaborate with community leaders, Panchayat members, and leaders of other grassroots organisation to co-plan strategies to deal with domestic violence cases in their respective localities

- Redefining safe shelters: France has decided to open up its hotels (lying unoccupied with the lockdown in place) as safe shelters for survivors of domestic violence; Spain has identified its drugstores as contact points where a survivor can drop a message for her rescue in case she is unable to call up the helpline numbers. While the latter initiative would take a lot of awareness spreading to drugstore staff and also ensuring that women are aware of this modality, the former, that of arranging shelters in currently unoccupied hotels and guesthouses, on government budget, is definitely doable.

- Need for acknowledgement and a protocol:The need to have a national guideline on how to deal with rising instances of domestic and intimate partner violence cannot be overemphasised. Standard Operating Procedures, as well as budgetary allotments are a prerequisite. India is not known for highlighting domestic violence as a major public health issue; however, since DV is a public health crisis, to have the Ministry of Health formally underline the urgency of the present situation would be extremely valuable in flagging off a major awareness drive. The policy level committees should focus on helping design a multi-ministry approach to responding to DV as well.

Unprecedented changes are taking place around us; we should be better prepared should a resurgence occur. We need to critically observe the changes, document them, learn from them and inform our protocols and policies accordingly.

Acknowledgements: The author acknowledges 'Sajha', her current project with CARE India (Bihar) which is focused on strengthening the health system's response to violence against women, particularly domestic violence in Bihar; Sajha has developed a response protocol for dealing with domestic violence survivors in times of the lockdown. The author also thanks Nobhojit Roy for his comments on an earlier version of this article.

\section{References}

1. Davies SE, Bennett B. A hindered human rights analysis of Ebola and Zika: locating gender in global health emergencies. Int Aff. 2016; 92(5):1041=60. DOI: https://doi.org/10.1111/1468-2346.12704).

2. Gender in Humanitarian Action Asia and the Pacific. The COVID-19 outbreak and gender: key advocacy points from Asia and the Pacific. 2020 Mar [cited 2020 Apr 14]. Available from: https://gbvaor.net/sites/ default/files/2020-03/GiHA\%20WG\%20advocacy\%20\%20brief\%20 final\%5B4\%5D.pdf

3. Papp S,Hersh M.A gender lens for COVID-19.Project Syndicate. 2020 Mar 27 [cited 2020 Apr 14]. Available from: https://www.project-syndicate. org/commentary/covid19-response-requires-a-gender-lens-by-susanpapp-and-marcy-hersh-2020-03

4. Baker T, Schell CO, Petersen DB, Sawe H, Khalid K, Mindolo S, et al. Essential care of critical illness must not be forgotten in the COVID-19 pandemic; Lancet; 2020 Apr 01;395(10232): 1253-54. https://doi. org/10.1016/S0140-6736(20)30793-5

5. GBV Sub-Sector Nigeria. Integrating gender in cholera prevention and control: interventions in North East Nigeria. 2017 Sep 7[cited 2020 Apr 14]. Available from: https://interagencystandingcommittee.org/ system/files/briefing_note-gender_in_cholera_response.pdf

6. Wenham C, Smith J, Morgan R. on behalf of the Gender and COVID 19 Working Group. COVID-19: The gendered impacts of the outbreak. Lancet. 2020 Mar 6[cited 2020 Apr 14;395(10227):846-8. Available from: https://www.thelancet.com/journals/lancet/article/PIIS01406736(20)30526-2/fulltext

7. CARE International. Gender implications of COVID-19 outbreaks in development and humanitarian settings. 2020 Mar 16 [cited 2020 Apr 14]. Available from: https://www.care-international.org/files/files/ Gendered_Implications_of_COVID-19_Full_Paper.pdf

8. Regional Risk Communication and Community Engagement Working Group. COVID-19: How to include marginalized and vulnerable people in risk communication and community engagement. 2020 Mar [cited 2020 Apr 14]. Available from: https://reliefweb.int/sites/reliefweb.int/ files/resources/COVID-19_CommunityEngagement_130320.pdf; p-4

9. World Health Organisation. Covid-19 and violence against women: What the health sector/system can do. 2020 Mar 26[cited 2020 Apr 14]. Available from:https://www.who.int/reproductivehealth/publications/ emergencies/COVID-19-VAW-full-text.pdf

10. UN News. UN chief calls for domestic violence'ceasefire' amid 'horrifying global upsurge'. 2020 Apr 6 [cited 2020Apr 14]. Available from: https:// news.un.org/en/story/2020/04/1061052

11. Graham-Harrison E., Giuffrida A, Smith H, Ford L. Lockdowns around the world bring rise in domestic violence. Guardian. 2020 Mar 28 [cited 2020 Apr 14]. Available from: https://www.theguardian.com/ society/2020/mar/28/lockdowns-world-rise-domestic-violence

12. CARE International. Sector-specific approaches to prioritise, adapt, and maintain programming in Covid-19 response. 2020 Apr 2 [cited 2020 Apr 14]. Available from: https://gbvguidelines.org/wp/wp-content/ uploads/2020/04/2020.04.02-CARE-COVIDSectorGuidance-CAREExternal.pdf 
13. Explained Desk. How countries are dealing with the surge in domestic violence under COVID-19 lockdown. Indian Express. 2020 Apr 6 [cited 2020 Apr 14]. Available from: https://indianexpress.com/article/ explained/how-countries-are-dealing-with-the-surge-in-domesticviolence-under-covid-19-lockdown-6350186/

14. Gearin M. Knight B. Family violence perpetrators using COVID-19 as a 'form of abuse we have not experienced before'. ABC News. 2020 Mar 29[cited 2020 Apr14]. Available from: https://www.abc net.au/news/2020-03-29/coronavirus-family-violence-surge-invictoria/12098546

15. World Health Organisation, London School of Hygiene and Tropical Medicine, and South African Medical Research Council. Global and regional estimates of violence against women: prevalence and health effects of intimate partner violence and nonpartner sexual violence. 2013 Mar; WHO, LSHTM, SAMRC; 2013[cited 2020 Apr 14]. Available from: https://apps.who.int/iris/bitstream/handle/10665/85241/WHO_ RHR_HRP_13.06_eng.pdf;jsessionid=3780B91D03A6CDBAD9BA4606 7B533FB3? sequence $=1$

16. Golder S.Measurement of domestic violence in NFHS surveys and some evidence.Oxfam India; 2018 [cited 2020 Apr 14]. Available from:https:// www.oxfamindia.org/sites/default/files/2018-10/WP-Measurementof-Domestic-Violence-in-National-Family-Health-Survey-surveys-and-
Some-Evidence-EN.pdf; p-4

17. PTI. Lockdown turns into captivity for women. Telegraph. $2020 \mathrm{Mar}$ 31[cited 2020 Apr 14]. https://www.telegraphindia.com/india/ lockdown-turns-into-captivity-for-women/cid/1760856

18. Sirur S, Krishnan R. Indian women are locked in with their abusers, but are finding new ways to seek help. Print. 2020 Apr 3[cited 2020 Apr 14]. Available from: https://theprint.in/india/indian-women-are-locked-inwith-their-abusers-but-are-finding-new-ways-to-seek-help/393949/

19. Chandra J. Covid-19 lockdown: rise in domestic violence, police apathy: NCW. Hindu. 2020 Apr 2[cited 2020 Apr 14]. Available from: https:// www.thehindu.com/news/national/covid-19-lockdown-spike-indomestic-violence-says-ncw/article31238659.ece

20. Bose A. India's domestic abuse survivors are in lockdown with their monsters, but helplines are not ringing. News 18.2020 Apr 6 [cited 2020 Apr 14]. Available from: https://www.news18.com/news/buzz/indiasdomestic-abuse-survivors-are-in-lockdown-with-their-monsters-butthe-helplines-are-not-ringing-2563955.html

21. Business Today. Coronavirus lockdown: WHO says domestic violence on rise, asks nations to take measures. 2020 Apr 5 [cited 2020 Apr 14]. Available from: https://www.businesstoday.in/latest/trends/ coronavirus-lockdown-who-says-domestic-violence-on-rise-asksnations-to-take-measures/story/400191.html

\section{The Covid-19 pandemic and India's cardiovascular disease burden: Finding the right balance}

\section{MEGHANA CHALASANI, KHURRAM NASIR, MOHIT D GUPTA, ANKUR KALRA}

\section{Abstract}

The national lockdown in India has (thus far) prevented a surge of Covid-19 cases. Due to crowded living conditions and poor social security, infectious spread may be difficult to contain and mitigate. India's healthcare system must respond to impending Covid-19 cases, as well as chronic, non-communicable diseases. Acute and chronic cardiovascular disease care have drastically decreased, suggesting reduced accessibility during the current pandemic. Neglecting chronic diseases may lead to permanent health damage and deaths that far exceed the negative outcomes of the pandemic alone. As businesses start to reopen, the healthcare system must find a balance in attending to Covid-19 rises amidst a significant chronic disease backdrop.

Authors: Meghana Chalasani (mchalasani@neomed.edu), Section of Cardiovascular Research, Heart, Vascular and Thoracic Department Cleveland Clinic Akron General, Akron, Ohio, USA; Khurram Nasir (knasir@ houstonmethodist.org), Division of Cardiovascular Prevention and Wellness, Houston Methodist DeBakey Heart \& Vascular Center Center for Outcomes Research, Houston Methodist, Houston, Texas, USA; Mohit D. Gupta (drmohitgupta@yahoo.com), Govind Ballabh Pant Hospital, New Delhi, INDIA; Ankur Kalra (corresponding author - kalraa@ccf.org), Department of Cardiovascular Medicine, Heart, Vascular and Thoracic Institute, Cleveland Clinic, Cleveland, Ohio, USA

To cite: Chalasani M, Nasir K, Gupta MD, Kalra A. The Covid-19 pandemic and India's cardiovascular disease burden: Finding the right balance. Indian J Med Ethics. 2020 Jul-Sep; 5(3) NS: 199-201. DOI: 10.20529/IJME.2020.059.

Published online on May 15, 2020.

Manuscript Editor:Vijayaprasad Gopichandran

(c) Indian Journal of Medical Ethics 2020
Keywords: India, Covid-19, cardiovascular disease, pandemic

\section{Background}

While the epicenters of the coronavirus disease 2019 (Covid-19) pandemic remain in the United States and Europe, concern for spread in developing countries should not be blind-sighted. Many Southeast Asian countries have a myriad public health concerns atop an impending infectious disease. On March 24, 2020, the Prime Minister of India, Mr Narendra Modi announced a national lockdown that has been extended until May 17, 2020, with different regulations based on regional viral spread (1). Physical distancing may not be feasible in a country with triple the population of the United States within one-third of the physical space, as well as fewer homeowners and less social security coverage. Although poverty in India is declining, $22 \%$ of Indian citizens lived below the poverty line of $\$ 1.25$ in 2011-2012, according to the United Nations Millennium Development Goals Programme (2). According to the Indian Ministry of Statistics and Programme Implementation, per-capita monthly income during 2019-2020 is estimated to be Rs. 11,254 , or about $\$ 150$ (3).

Further compounding these challenges, it is important to remember that the workforce of India does not experience the same protections and support that Western nations have adopted (4). India's employment-based plan for social security is limited to business units employing a minimum number of employees. In the economic census of 2013-2014, it was reported that $98.6 \%$ of all establishments employed less than ten workers (4). Most of these individuals do not have social 